\title{
Linguistic and psychometric validation of Sinhala version of Menopause Specific Quality of Life questionnaire
}

\author{
Nirmala Rathnayake ${ }^{* 1}$, Gayani Alwis ${ }^{2}$, Janaka Lenora ${ }^{3}$, Iresha Mampitiya ${ }^{4}$ and Sarath Lekamwasam ${ }^{5}$ \\ ${ }^{1}$ Department of Nursing, Faculty of Allied Health Sciences, University of Ruhuna, Sri Lanka. \\ ${ }^{2}$ Department of Anatomy, Faculty of Medicine, University of Ruhuna, Sri Lanka. \\ ${ }^{3}$ Department of Physiology, Faculty of Medicine, University of Ruhuna, Sri Lanka. \\ ${ }^{4}$ Department of Gynecology and Obstetrics, Faculty of Medicine, University of Ruhuna, Sri Lanka. \\ ${ }^{5}$ Population Health Research Centre, Department of Medicine, Faculty of Medicine, University of Ruhuna, Sri Lanka.
}

\begin{abstract}
Menopause Specific Quality of Life (MENQOL) questionnaire assesses the health related quality of life (HRQOL) of postmenopausal women (PMW). It includes 29 menopausal discomforts distributed among four main domains, namely, vasomotor, psychosocial, physical and sexual. This study was designed for linguistic validation of the Sinhala version of MENQOL questionnaire and evaluation of its psychometric properties. The Sinhala version of MENQOL questionnaire was adapted following a standard methodology of linguistic validation, including_forward translation, backward translation, patient testing and proof reading. It was selfadministered among 200 PMW, aged 56.0 \pm 3.3 years, selected randomly from Galle, Sri Lanka, along with the previously validated Menopause Rating Scale (MRS). Two weeks after the previous administration, the MENQOL questionnaire was administered again among a sub-group of PMW $(n=100)$ selected from the 200 PMW. Then, the psychometric properties including reliability and validity were evaluated. The MENQOL questionnaire showed a high test re-test reliability measured with intraclass correlation $=0.98(0.97-0.99)$. The global Cronbach's alpha was 0.95 , indicating higher internal consistency. Seven factors with Eigen value exceeding one, explaining $77.11 \%$ of cumulative variance, were observed in Factor Analysis with Principal Component Analysis. It showed more explanatory factor extraction. Strong significant positive correlation between MENQOL questionnaire score and MRS score $(r=0.78, p<0.001)$ was observed, which confirms the concurrent validity. It was observed that the self-administered, 29 item, Sinhala version of MENQOL questionnaire is a reliable and a valid menopause specific tool with satisfactory psychometric properties. Therefore, MENQOL questionnaire can be recommended to measure the menopausal discomforts and HRQOL of Sinhala speaking Sri Lankan PMW.
\end{abstract}

Keywords: Linguistic validation, menopause, menopause specific quality of life questionnaire, reliability, validity.

\section{INTRODUCTION}

Menopause is associated with biological changes that obligate a negative impact on health related quality of life (HRQOL) of middle-aged women. In postmenopausal women (PMW), the quality of life (QOL) usually denotes the features which are an aggregation of menopausal discomforts affecting their health without focusing on their general physical, psychological or environmental aspects of health (Forouhari et al., 2010). Hence, the QOL specific to PMW often refers to the menopausal discomforts, which adversely impact on the aspects of personal health and self-satisfaction (Forouhari et al., 2010). Menopausal discomforts lead to impairment of HRQOL and directly impact on the day-to-day activities including their home, work and recreational tasks (Williams et al., 2008).

In 1990, there were around 467 million women aged $\geq 50$ years in the world. This number is expected to reach 1,200 million by the year 2030 (von Mühlen et al., 1995). Furthermore, in Sri Lanka, nearly one fourth of the women population is over 50 years (Sri Lanka, Department of Census and Statistics, 2014) and is considered to be postmenopausal. This number is expected to increase with the advancement of health technology and inventions which leads to improved

${ }^{*}$ Corresponding author (nirmala.priyanthi@gmail.com ; iD https://orcid.org/0000-0002-0666-2975)

This article is published under the Creative Commons CC-BY-ND License (http://creativecommons.org/licenses/ 
health care. Further, the life expectancy of women is increasing worldwide and in most countries, women would live approximately more than one third of their life after menopause. Health and wellbeing of PMW, therefore, has become an essential component in the contemporary healthcare system.

Clinicians need to pay special attention to menopause related symptoms of women in order to provide comprehensive and holistic care. The identification of menopausal symptoms, their severity and finally HRQOL is vital, in proper evaluation of women in the postmenopausal age (Kothiyal \& Sharma, 2013). Several instruments have been developed to quantify the menopausal discomforts and HRQOL (Zöllner et al., 2005), and these includes the Menopause Rating Scale (MRS) (Schneider et al., 2000), Kupperman Index (Kupperman et al., 1953) and Menopause Specific Quality of Life (MENQOL) questionnaire (Hilditch et al., 1996). Among them, MENQOL questionnaire is the widely used tool (Jenabi et al., 2015) in research and clinical evaluation because of its descriptive nature, ability to determine the severity of symptoms and easy applicability.

It was introduced in 1996 by Hilditch et al. as a patientreported outcome (PRO) tool for measuring MENQOL in early menopause; duration since menopause two to seven years (Hilditch et al., 1996). MENQOL questionnaire contains 29 items (menopausal discomforts) to capture the HRQOL in four main domains (Hilditch et al., 1996): vasomotor-3 items (1-3), psychosocial-7 items (4-10), physical- 16 items (11-26) and sexual-3 items (27-29). HRQOL of previous 30 days is assessed through evaluating both frequency and severity of all 29 menopausal discomforts in a seven point Likert scale. MENQOL questionnaire has been translated to more than 20 languages in the West and more than 11 languages in the Asian and South Asian countries with or without ensuring its psychometric properties (Sydora et al., 2016). Further, it has been used in numerous clinical settings in different ethnic populations worldwide (Sydora et al., 2016), including Asian and South Asian countries (Chen et al., 2008; Nisar \& Sohoo, 2009; Williams et al., 2009; Shobeiri et al., 2016). However, it has not been translated or validated in the Sri Lankan context so far.

In Sri Lanka, HRQOL of PMW is not appropriately assessed in clinical settings or in research, partly due to lack of proper instruments. The researchers identified the importance of having a validated questionnaire that would provide the reproducibility and validity of study findings that are generated based on a MENQOL tool in Sri Lanka.
Hence, the current study was done to generate a questionnaire to assess the discomfort specific to menopause and thereby determine the HRQOL of local PMW. In this study linguistic validation of MENQOL questionnaire into the Sinhala language and evaluation of its psychometric properties were performed.

\section{METHODOLOGY}

\section{Study design, setting and participants}

The current validation study was carried out in Galle district; Bope-Poddala Medical Officer of Health (MOH) area in Southern Sri Lanka, during January 2017 April 2018. Healthy, community dwelling, naturally menopaused women with an intact uterus and two to seven years duration since menopause participated in the study. The duration since menopause was selected according to the MENQOL developer's guidelines (Hilditch et al., 1996). Moreover, PMW who had chronic medical and surgical conditions (non-communicable diseases, cancers etc.), psychiatric disorders, debilities and injuries of musculoskeletal system, women on hormone replacement therapy and women with endocrine disorders (diabetes, thyroid disorders etc.) were excluded. Self-reported menstrual history was used to determine the postmenopausal status, based on classification of Stages of Reproductive Aging Workshop (Harlow et al., 2012). It was defined as absence of menstruation for a period of 12 months following the last menstruation.

\section{Sample size calculation and sampling procedure}

Sample size calculation was based on five respondents into one variable ratio (Hair et al., 1995). Another 10\% was added to compensate the non-respondents and incomplete questionnaires; total sample size was 160 women.

Multistage cluster sampling technique was used for the selection of PMW. Three public health midwives (PHM) divisions (the smallest primary health care unit) were randomly selected out of eighteen PHM divisions in the Bope-Poddala $\mathrm{MOH}$ area. Women aged above 45 years and below 60 years were identified using household registers of selected areas as guides, with the support of the administrative officer of each division (Grama Niladari; GN) belonging to each selected PHM area. Houses were arranged in a single list and those who got the odd numbers were included in the study to achieve randomization. If one particular house had more than one woman in the given age range, only one woman was included to the study. Even though calculation of sample gives only 160 , the research team was able to recruit 200 women for the study, following the sampling procedure during the time period. 


\section{Linguistic validation of MENQOL questionnaire into Sinhala language}

The linguistic validation guidelines described by Mapi Research Trust Information Support Unit were followed for cross cultural adaptation of the Sinhala version of MENQOL questionnaire i.e., forward translation, backward translation, patient testing and proof reading.

The original English version was translated (forward translation) to Sinhala by two independent health professionals; a medical officer and a nurse who were fluent in both Sinhala and English languages. One was informed about the purpose of translation while the other was not informed. Each one produced an independent forward translation of the original items, instructions and response choices. Then the items were consolidated into a single questionnaire and synthesised as a common translation to maximise the clarity of items by the investigators. This Sinhala version was conceptually equivalent to the original questionnaire. This was easy to be understood by Sinhala people. There were no interpretation problems of the original version.

The synthesised translation was translated back into English (backward translation) by another two independent health professionals, fluent in both Sinhala and English languages, to assess the comparability with the original version and to make sure that there were no gross inconsistencies or conceptual errors. Backward translators had no access to the original version. Both back translations were combined by the investigator, compared with the original version and a pre-final Sinhala version was created.

When deciding the pre-final version, conceptual equivalence with the original version and cultural relevance to the Sinhala language was observed. A group of experts (gynecologist, physician, physiologist, anatomist, and nursing academic and forward and backward translators) independently reviewed all the versions of the MENQOL questionnaire and ensured its content validity.

The pre-final version was further assessed in a focus group discussion (FGD) with 10 PMW between 4560 years of age, who were healthy, and who recently underwent menopause (two to seven years of menopausal duration) naturally. During the FGD, the acceptability, understandability, simplicity and appropriateness were evaluated and further, interpretation problems were evaluated. There were no problems encountered and therefore, the final version was decided.

The final Sinhala version of MENQOL questionnaire underwent a proof reading process to detect any typing, spelling or grammatical mistakes by two Sinhalese nursing academics. The final version was pre-tested among 30 PMW with above inclusion criteria with different education background selected from another $\mathrm{MOH}$ area in the Galle district and the face validity was ensured.

\section{Administration of the Sinhala version of MENQOL questionnaire}

The Sinhala version of MENQOL questionnaire that was adapted following the standard guidelines and the Sinhala version of MRS (Rathnayake et al., 2018) were self-administered among 200 PMW. All women answered the questionnaire and there were no incomplete questionnaires. After two weeks of first administration, the MENQOL questionnaire was re-administered among a randomly selected sub-group $(\mathrm{n}=100)$ of PMW who participated at the first administration.

In the MENQOL questionnaire, the presence or absence of menopausal discomforts (29 items) were marked and the severity was also assessed with a Likert scale (seven point); zero (absence of discomforts) to six (extremely bothered by discomforts) within the previous month (Hilditch et al., 1996). These 29 items of menopausal discomforts are designed to measure the HRQOL under four main domains (Hilditch et al., 1996) namely: vasomotor-3 items (1-3), psychosocial-7 items (4-10), physical- 16 items (11-26) and sexual-3 items (27-29). The item scores were then converted to scores ranging from 1-8: absence of discomforts $=$ 1 , discomforts are experienced but did not bother $=$ 2 , and through to extremely bothered $=8$ (Hilditch et al., 1996).

The MRS is a validated tool for PMW in Sri Lanka (Rathnayake et al., 2018), that describes 11 menopausal discomforts, including somato-vegetative discomforts: items 1-3 and 11; psychological discomforts: items 4-7; and urogenital discomforts: items $8-10$. If the women had experienced each discomfort within the previous month, they were asked to indicate it in a severity scale, from a zero (no discomforts at all) to four (very severe) in a five-point Likert scale. The higher ratings indicate higher intensity of difficulties and their severity (Heinemann et al., 2004).

\section{Psychometric properties of the Sinhala version of MENQOL questionnaire}

Reliability and the validity of the Sinhala version of questionnaire were considered. Reliability was evaluated using test-retest reliability and internal 
consistency. Test-retest reliability was measured using the intraclass correlation (ICC) evaluation by comparing overall MENQOL questionnaire score at first and subsequent administrations (Arafat et al., 2016). Internal consistency was assessed with the Cronbach's alpha for overall score and computed for each subscale at baseline. Acceptable Cronbach's alpha value was considered as $\geq$ 0. 7 (Field, 2009).

Validity of the questionnaire was evaluated considering convergent validity, construct validity, discriminant validity and concurrent validity. Convergent validity was tested by item-domain correlation, considering higher correlation of each item with their respective subscale. Construct validity was evaluated by factor analysis (FA) performed with principle component analysis (PCA)while keeping Varimax with Keiser normalization as rotation method. The Kaiser-Meyer-Olkin (KMO) and Bartlett's test of Sphericity statistics were analysed and correlation matrix was observed to determine whether FA was appropriate for the data, mainly for sampling adequacy assessment (KMO $>0.7)$, multicollinearity assessment (many coefficients in correlation matrix should be 0.3 and above), Bartlett's Test of Sphericity (should reach statistical significance) and Commonalities Coefficients (should be >0.6) (Arafat et al., 2016). The number of extracted components was determined by the Scree plot, percentage of variance explained by each component and number of Eigen values over one (Kaiser-Guttman rule).

Items were considered representative of a component if their individual item loading was $\geq 0.40$ and in the cross-loading items, the factor, which had higher loading value, was taken as the respective factor (Arafat et al., 2016).

In discriminant validity analysis, mean $\pm \mathrm{SD}$ of each item was compared between the asymptomatic and symptomatic PMW, using independent sample t-test. Severity of menopausal discomforts was considered when deciding the asymptomatic and symptomatic women. Women who did not experience menopausal discomfort and who experienced discomforts but, did not bother with such discomforts (in Likert scale; $1-2$ ) were considered as asymptomatic women. Women who experienced bothersome discomforts of any degree (mild to extremely bothered discomforts) were considered as symptomatic women (in Likert scale; 3-8).

The correlation between the overall scores of the MENQOL questionnaire and the MRS was assessed to evaluate the concurrent validity (Arafat et al., 2016); the Pearson correlation coefficients and Kendall's tau-b value were observed. Furthermore, a categorical analysis was done by cross tabulating the quartiles of the total scores of MENQOL questionnaire and MRS to test the agreement between the two tools using the Cohen's Kappa value (Arafat et al., 2016).

\section{Statistical analysis}

The basic characteristics of PMW who participated in the evaluation of psychometric properties were presented as frequencies (percentages) or Mean \pm SD. Psychometric properties of the questionnaire were evaluated. SPSS 20.0 version was used for the data analysis. Statistical significance was considered as $\mathrm{p}$ value $<0.05$. Considered strengths of correlations were: between 0.10 and 0.29 - weak; between 0.30 and 0.49 - moderate; and between 0.50 and 1.00 - strong (Field, 2009).

\section{Ethical considerations}

Permission from the relevant publishers of MENQOL questionnaire, the Mapi Research Trust Information Support Unit, France, was obtained prior to the commencement of the process. Ethics Review Committee, Faculty of Medicine, University of Ruhuna, Sri Lanka granted the ethical clearance for this study (Reference number; 24.09.2014:3.2). All procedures were in agreement with the ethical standards of the Helsinki Declaration. Informed consent was signed by all individual study participants before the commencement of the data collection.

\section{RESULTS AND DISCUSSION}

\section{Results}

\section{Characteristics of the participants}

Socio-demographic characteristics of PMW who participated in psychometric properties analyses are shown in Table 1. Age, age at menopause and duration since menopause (Mean \pm SD) of the evaluated PMW were $56.3 \pm 3.3$ years, $50.7 \pm 2.8$ years and $5.6 \pm 1.8$ years, respectively.

The prevalence of night sweats, muscle and joint aches, feeling tired or worn out and low backaches were higher $(>82 \%)$ and the prevalence of increased facial hair, sweating, avoiding intimacy and feeling of wanting to be alone were lower $(<50 \%)$ among the studied PMW (Table 2). Further, scores (Mean $\pm \mathrm{SD}$ ) of vasomotor, physical, psychosocial and sexual domains and overall score were $2.51 \pm 1.23,2.31 \pm 1.28,2.89 \pm 1.04,2.74 \pm 1.61$ and $10.46 \pm 4.26$, respectively. 
Table 1: Sociodemographic characteristics of the PMW participated in the study $(n=200)$

\begin{tabular}{llr}
\hline Characteristics & Sub category & $\begin{array}{r}\text { Frequency (\%) } \\
\text { or }\end{array}$ \\
& & Mean (SD) \\
\hline Age (years) & & $56.3(3.3)$ \\
Age at menopause (years) & & $50.7(2.8)$ \\
Duration since menopause (years) & & $5.6(1.8)$ \\
Employment status & Employed & $45(22.5 \%)$ \\
& Non employed & $155(77.5 \%)$ \\
Civil status & Married & $179(89.5 \%)$ \\
Living companion & Single, widowed or divorced & $21(10.5 \%)$ \\
& With husband and children & $114(57.0 \%)$ \\
& With husband or children & $65(32.5 \%)$ \\
Education status & Alone or living with others & $21(10.5 \%)$ \\
& Primary education & $95(47.5 \%)$ \\
& Secondary education & $49(24.5 \%)$ \\
Monthly income & Upper secondary education, degree or diploma & $56(28.0 \%)$ \\
& Below 20,000 LKR & $157(78.5)$ \\
\hline
\end{tabular}

$\overline{\mathrm{LKR}}=$ Sri Lankan rupees $(150 \mathrm{LKR}=1 \mathrm{USD}), \mathrm{PMW}=$ postmenopausal women living with others include; parents, siblings, friends or other relatives

\section{Psychometric properties of the Sinhala version of MENQOL questionnaire}

Reliability and internal consistency: ICC was 0.98 (95\% $\mathrm{CI}=0.97-0.99)$ in the overall MENQOL score, which indicate a higher test-retest reliability. The MENQOL questionnaire showed a higher internal consistency; global Cronbach's alpha; for overall MENQOL $=0.95$, vasomotor domain $=0.83$, psychosocial domain $=0.93$, physical domain $=0.90$ and sexual domain $=0.89(p<0.001)$.

Convergent validity: All items in the MENQOL questionnaire correlated more strongly $(r>0.50, p<0.001)$ with their respective domain than the other domains (Table 3) indicating higher convergence in item-domain correlation analysis.

Construct validity: Seven factors with Eigen value exceeding one, explaining $77.11 \%$ of cumulative variance, were observed in the FA based on PCA (each factor responsible for $43.81 \%, 8.79 \%, 5.91 \%, 5.72 \%, 4.77 \%$, $4.42 \%$ and $3.65 \%$ of variance, respectively) (Table 4 ). The items saturated in to factor one were all the psychosocial discomforts in original tool (item 4-10). Three physical discomforts (aches in back of neck or head, decrease in stamina and dry skin) were saturated together with all the sexual discomforts in factor two. Pure physical discomforts (flatulence, weight gain, increased fa- cial hair, changes in appearance, feeling bloated) were saturated together in factor three. Combination of both physical and mental discomforts (feeling tired, difficulty in sleeping, decrease in strengths and lack of energy even though they are in physical domain in original tool) were saturated in to factor four. Factor five comprised of all three vasomotor discomforts, saturated together as in the original tool (Hilditch et al., 1996). The two main musculoskeletal discomforts (aching in muscles and joints and low backache) were saturated in factor six. Two urinary discomforts (frequent urination and involuntary urination) were saturated together in factor seven (Table 4). As results suggested, the new seven factors, (factor 1-7), were named as, psychosocial, physio-sexual, physio-psychological, physical, vasomotor, musculoskeletal and urinary domains, respectively, in the Sinhala version.

Discriminant validity: Severity scores (Mean $\pm \mathrm{SD}$ ) of all 29 items (menopausal discomforts) were significantly different $(\mathrm{p}<0.001)$ between the asymptomatic and symptomatic women approving good discriminant validity (data not shown in a table).

Concurrent validity: Overall MENQOL score strongly correlated with the overall MRS scores ( $r=0.76$, Kendall's tau- $b=0.65 ; \mathrm{p}<0.001$ ), assuring strong concurrent validity. Further, when the quartiles of the overall scores of the two scales were cross tabulated to evaluate the 
Table 2: Prevalence of menopausal discomforts among PMW participated in the study $(\mathrm{n}=200)$

\begin{tabular}{|c|c|c|c|}
\hline \multirow{2}{*}{$\begin{array}{l}\text { Item } \\
\text { No. }\end{array}$} & \multirow[t]{2}{*}{ Item } & \multicolumn{2}{|c|}{ Prevalence of menopausal discomforts } \\
\hline & & Asymptomatic women [n (\%)] & Symptomatic women $[\mathrm{n}(\%)]$ \\
\hline 1 & Hot flushes or flashes & $67(33.5)$ & $133(66.5)$ \\
\hline 2 & Night sweats & $35(17.5)$ & $165(82.5)$ \\
\hline 3 & Sweating & $105(52.5)$ & $95(47.5)$ \\
\hline 4 & Dissatisfaction with my personal life & $73(36.5)$ & $127(63.5)$ \\
\hline 5 & Feeling anxious or nervous & $67(33.5)$ & $133(66.5)$ \\
\hline 6 & Poor memory & $84(42.0)$ & $116(58.0)$ \\
\hline 7 & Accomplishing less than I used to & $76(38.0)$ & $124(67.0)$ \\
\hline 8 & Feeling depressed, down or blue & $93(46.5)$ & $107(53.5)$ \\
\hline 9 & Being impatient with other people & $94(47.0)$ & $106(53.0)$ \\
\hline 10 & Feeling of wanting to be alone & $110(55.0)$ & $90(45.0)$ \\
\hline 11 & Flatulence (wind) or gas pains & $74(37.0)$ & $126(63.0)$ \\
\hline 12 & Aching in muscles and joints & $16(8.0)$ & $184(92.0)$ \\
\hline 13 & Feeling tired or worn out & $35(17.5)$ & $165(82.5)$ \\
\hline 14 & Difficulty in sleeping & $70(35.0)$ & $130(65.0)$ \\
\hline 15 & Aches in back of neck or head & $53(26.5)$ & $147(73.5)$ \\
\hline 16 & Decrease in physical strength & $49(24.5)$ & $151(75.5)$ \\
\hline 17 & Decrease in stamina & $48(24.0)$ & $152(76.0)$ \\
\hline 18 & Lack of energy & $40(20.0)$ & $160(80.0)$ \\
\hline 19 & Dry skin & $41(20.5)$ & $159(79.5)$ \\
\hline 20 & Weight gain & $83(41.5)$ & $117(58.5)$ \\
\hline 21 & Increased facial hair & $114(57.0)$ & $86(43.0)$ \\
\hline 22 & Changes in appearance, texture or tone of my skin & $42(21.0)$ & $158(79.0)$ \\
\hline 23 & Feeling bloated & $99(49.5)$ & $101(50.5)$ \\
\hline 24 & Low backache & $14(7.0)$ & $186(93.0)$ \\
\hline 25 & Frequent urination & $55(27.5)$ & $145(72.5)$ \\
\hline 26 & Involuntary urination when laughing or coughing & $70(35.0)$ & $130(65.0)$ \\
\hline 27 & Decrease in my sexual desire & $60(30.0)$ & $140(70.0)$ \\
\hline 28 & Vaginal dryness & $80(40.0)$ & $120(60.0)$ \\
\hline 29 & Avoiding intimacy & $102(51.0)$ & $98(49.0)$ \\
\hline
\end{tabular}

Asymptomatic $=$ Women not bothersome with menopausal symptoms Symptomatic $=$ Women bothered mild - extremely with menopausal discomforts PMW $=$ postmenopausal women 
Table 3: Item-domain correlation analysis of Sinhalese version of MENQOL (29 items, 4 domains)

\begin{tabular}{|c|c|c|c|c|c|c|}
\hline $\begin{array}{l}\text { Item } \\
\text { No. }\end{array}$ & Item & $\begin{array}{r}\text { Physical } \\
\text { domain } \\
\text { (16 items) }\end{array}$ & $\begin{array}{r}\text { Psychosocial } \\
\text { domain } \\
(7 \text { items })\end{array}$ & $\begin{array}{r}\text { Vasomotor } \\
\text { domain } \\
(3 \text { items })\end{array}$ & $\begin{array}{r}\text { Sexual } \\
\text { domain } \\
(3 \text { items })\end{array}$ & $\begin{array}{r}\text { Overall } \\
\text { MENQOL } \\
\text { (29 items) }\end{array}$ \\
\hline 1 & Hot flushes or flashes & 0.62 & 0.43 & 0.85 & 0.45 & 0.66 \\
\hline 2 & Night sweats & 0.53 & 0.38 & 0.94 & 0.35 & 0.58 \\
\hline 3 & Sweating & 0.30 & 0.26 & 0.81 & 0.24 & 0.39 \\
\hline 4 & Dissatisfaction with my personal life & 0.52 & 0.77 & 0.39 & 0.37 & 0.61 \\
\hline 5 & Feeling anxious or nervous & 0.72 & 0.79 & 0.46 & 0.53 & 0.77 \\
\hline 6 & Poor memory & 0.72 & 0.90 & 0.40 & 0.62 & 0.80 \\
\hline 7 & Accomplishing less than I used to & 0.72 & 0.83 & 0.30 & 0.52 & 0.76 \\
\hline 8 & Feeling depressed, down or blue & 0.67 & 0.88 & 0.27 & 0.55 & 0.74 \\
\hline 9 & Being impatient with other people & 0.65 & 0.85 & 0.30 & 0.56 & 0.73 \\
\hline 10 & Feeling of wanting to be alone & 0.59 & 0.83 & 0.28 & 0.41 & 0.66 \\
\hline 11 & Flatulence (wind) or gas pains & 0.70 & 0.48 & 0.41 & 0.43 & 0.66 \\
\hline 12 & Aching in muscles and joints & 0.63 & 0.40 & 0.29 & 0.42 & 0.59 \\
\hline 13 & Feeling tired or worn out & 0.72 & 0.61 & 0.51 & 0.52 & 0.73 \\
\hline 14 & Difficulty in sleeping & 0.78 & 0.67 & 0.58 & 0.58 & 0.80 \\
\hline 15 & Aches in back of neck or head & 0.71 & 0.50 & 0.52 & 0.55 & 0.70 \\
\hline 16 & Decrease in physical strength & 0.65 & 0.52 & 0.14 & 0.35 & 0.59 \\
\hline 17 & Decrease in stamina & 0.70 & 0.66 & 0.32 & 0.63 & 0.72 \\
\hline 18 & Lack of energy & 0.75 & 0.62 & 0.23 & 0.54 & 0.71 \\
\hline 19 & Dry skin & 0.68 & 0.54 & 0.41 & 0.58 & 0.68 \\
\hline 20 & Weight gain & 0.60 & 0.31 & 0.61 & 0.30 & 0.56 \\
\hline 21 & Increased facial hair & 0.50 & 0.33 & 0.21 & 0.39 & 0.47 \\
\hline 22 & $\begin{array}{l}\text { Changes in appearance, texture or tone of my } \\
\text { skin }\end{array}$ & 0.62 & 0.38 & 0.39 & 0.47 & 0.59 \\
\hline 23 & Feeling bloated & 0.73 & 0.56 & 0.50 & 0.50 & 0.72 \\
\hline 24 & Low backache & 0.49 & 0.26 & 0.16 & 0.32 & 0.43 \\
\hline 25 & Frequent urination & 0.52 & 0.35 & 0.43 & 0.36 & 0.51 \\
\hline 26 & Involuntary urination when laughing or coughing & 0.46 & 0.29 & 0.34 & 0.37 & 0.45 \\
\hline 27 & Decrease in my sexual desire & 0.58 & 0.47 & 0.32 & 0.89 & 0.65 \\
\hline 28 & Vaginal dryness & 0.71 & 0.60 & 0.46 & 0.92 & 0.78 \\
\hline 29 & Avoiding intimacy & 0.64 & 0.57 & 0.34 & 0.90 & 0.71 \\
\hline
\end{tabular}

Pearson correlation was significant at $<0.001$ level.

Boldness indicates the corresponding items of the subscales. 
Table 4: Seven factors extracted by the factor analysis with varimax rotation (29 items)

\begin{tabular}{|c|c|c|c|c|c|c|c|c|c|}
\hline \multirow{2}{*}{$\begin{array}{l}\text { Domain (as } \\
\text { in original } \\
\text { tool) }\end{array}$} & \multirow{2}{*}{$\begin{array}{l}\text { Item } \\
\text { No. }\end{array}$} & \multirow{2}{*}{ Items } & \multicolumn{7}{|c|}{ Factor (as EFA suggested in this study) } \\
\hline & & & 1 & 2 & 3 & 4 & 5 & 6 & 7 \\
\hline \multirow{3}{*}{$\begin{array}{l}\text { Vasomotor } \\
\text { domain }\end{array}$} & 1 & Hot flushes or flashes & & & 0.52 & & 0.61 & & \\
\hline & 2 & Night sweats & & & & & 0.86 & & \\
\hline & 3 & Sweating & & & & & 0.85 & & \\
\hline \multirow[t]{7}{*}{$\begin{array}{l}\text { Psychosocial } \\
\text { domain }\end{array}$} & 4 & $\begin{array}{l}\text { Dissatisfaction with my } \\
\text { personal life }\end{array}$ & 0.70 & & & & & & \\
\hline & 5 & Feeling anxious or nervous & 0.53 & & & 0.49 & & & \\
\hline & 6 & Poor memory & 0.75 & & & & & & \\
\hline & 7 & $\begin{array}{l}\text { Accomplishing less than I } \\
\text { used to }\end{array}$ & 0.74 & & & & & & \\
\hline & 8 & $\begin{array}{l}\text { Feeling depressed, down } \\
\text { or blue }\end{array}$ & 0.75 & & & & & & \\
\hline & 9 & $\begin{array}{l}\text { Being impatient with other } \\
\text { people }\end{array}$ & 0.76 & & & & & & \\
\hline & 10 & $\begin{array}{l}\text { Feeling of wanting to be } \\
\text { alone }\end{array}$ & 0.82 & & & & & & \\
\hline \multirow[t]{17}{*}{$\begin{array}{l}\text { Physical } \\
\text { domain }\end{array}$} & 11 & $\begin{array}{l}\text { Flatulence (wind) or gas } \\
\text { pains }\end{array}$ & & & 0.53 & 0.51 & & & \\
\hline & 12 & $\begin{array}{l}\text { Aching in muscles and } \\
\text { joints }\end{array}$ & & & & & & 0.83 & \\
\hline & 13 & Feeling tired or worn out & & & & 0.59 & & & \\
\hline & 14 & Difficulty in sleeping & & & & 0.45 & & & \\
\hline & 15 & $\begin{array}{l}\text { Aches in back of neck or } \\
\text { head }\end{array}$ & & 0.43 & & & 0.41 & & \\
\hline & 16 & $\begin{array}{l}\text { Decrease in physical } \\
\text { strength }\end{array}$ & & & & 0.78 & & & \\
\hline & 17 & Decrease in stamina & & 0.63 & & 0.41 & & & \\
\hline & 18 & Lack of energy & & 0.41 & & 0.69 & & & \\
\hline & 19 & Dry skin & & 0.56 & 0.49 & & & & \\
\hline & 20 & Weight gain & & & 0.70 & & 0.43 & & \\
\hline & 21 & Increased facial hair & & & 0.70 & & & & \\
\hline & 22 & $\begin{array}{l}\text { Changes in appearance, } \\
\text { texture or tone of my skin }\end{array}$ & & 0.43 & 0.59 & & & & \\
\hline & 23 & Feeling bloated & & & 0.69 & & & & \\
\hline & 24 & Low backache & & & & & & 0.89 & \\
\hline & 25 & Frequent urination & & & & & & & 0.77 \\
\hline & 26 & Involuntary urination when & & & & & & & 0.78 \\
\hline & & laughing or coughing & & & & & & & \\
\hline \multirow{3}{*}{$\begin{array}{l}\text { Sexual } \\
\text { domain }\end{array}$} & 27 & Decrease in my sexual & & 0.73 & & & & & \\
\hline & & $\begin{array}{l}\text { desire } \\
\text { Vaginal dryness }\end{array}$ & & 0.72 & & & & & \\
\hline & $\begin{array}{l}28 \\
29\end{array}$ & $\begin{array}{l}\text { vaginal aryness } \\
\text { Avoiding intimacy }\end{array}$ & & 0.75 & & & & & \\
\hline
\end{tabular}

Extraction method: Principal Component Analysis, Rotation Method: Varimax with Kaiser Normalization 
Table 5: Agreement between quartiles of the MRS and MENQOL

\begin{tabular}{|c|c|c|c|c|}
\hline \multirow{3}{*}{ MRS score } & \multicolumn{3}{|c|}{ MENQOL score } & \multirow{3}{*}{$\begin{array}{r}\text { Quartile 4 } \\
(>14.04)\end{array}$} \\
\hline & Quartile 1 & Quartile 2 & Quartile 3 & \\
\hline & $(<6.77)$ & $(6.77-10.51)$ & $(10.51-14.04)$ & \\
\hline Quartile $1(<8.0)$ & 37 & 11 & 0 & 2 \\
\hline Quartile 2 (8.0-13.5) & 8 & 28 & 8 & 6 \\
\hline Quartile 3 (13.5-20.0) & 4 & 7 & 35 & 3 \\
\hline Quartile $4(>20.0)$ & 2 & 3 & 16 & 30 \\
\hline
\end{tabular}

Cohen's Kappa $=0.50$, Standard error $=0.04, \mathrm{p}<0.001$

agreement between two scales, the Cohen's Kappa value was $0.54(\mathrm{SE}=0.04, \mathrm{p}<0.001)$, indicating a moderate strength of agreement of the two scales (Table 5).

\section{Discussion}

In this study, the newly adapted Sinhala version of the MENQOL questionnaire showed satisfactory psychometric properties indicating that it is a valid and reliable instrument to evaluate menopausal discomforts, their severity and HRQOL of Sinhala speaking PMW.

This study observed higher internal consistency, item-domain correlation in the new version of MENQOL questionnaire with seven factors emerging in the FA. Furthermore, it showed a good discriminant and criterion validity, sensitive enough in evaluating menopausal discomforts, their severity and HRQOL in PMW. The observed high internal consistency (Cronbach's alpha; 0.95 ) in the current study was concordant with other studies done in different countries; Turkey (0.97) (Malhan et al., 2008), China (0.90) (Nie et al., 2017), USA (individual domain between 0.78-0.86) (Van Dole et al., 2012) and Iran (Persian version, 0.90) (Ghazanfarpour et al., 2014) and the original MENQOL questionnaire development study (0.8-0.89) (Hilditch et al., 1996). The item-domain correlation was also concordant with the Chinese validation of MENQOL questionnaire (Nie et al., 2017). However, discordance with the validated Persian version, where there were minor correlations in physical and sexual domains, was observed (Ghazanfarpour et al., 2014).

The first FA (Hilditch et al., 1996) suggested four main domains. However, in the current analysis, seven factors were extracted, explaining the $77 \%$ of total variance. Somewhat similar factor extraction, six factors, has been observed in the Chinese validation (Nie et al., 2017). However, the Turkish validation (Malhan et al., 2008) revealed a factor extraction similar to the original version, explaining $78.9 \%$ variability. Higher internal consistency and item-domain correlation among the studies is indicative of adequate consistency of the questionnaire and it works in similar pattern in different countries.

Further, in FA, two factors (psychosocial and vasomotor) were completely similar to the original structure with few unexpected factor extractions in which three items in the sexual domain were saturated together with physical discomforts. The possibility of having a combination of two extremes of discomforts together in one factor cannot be illustrated. The menopausal discomforts affecting HRQOL of PMW probably would be due to the fact that the QOL is a subjective perception dependent on their internal value system (Saxena et al., 1997) and the cultural or territorial variations of perception on menopausal discomforts of PMW from different backgrounds. Further, findings of the current FA was more explanatory than the original tool, because FA extracted urinary discomforts together; musculoskeletal discomforts together; sexual discomforts together; and discomforts which cannot be distinguished as physical and psychological aspects together. This is somewhat consistent with the factor extraction observed in the Chinese version validation (Nie et al., 2017). It was deemed that keeping urinary and sexual discomforts in separate domains is more appropriate than combining them with another domain; keeping them together with physical discomforts may dilute the severity of urinary discomforts scores. One possible reason for the saturation of musculoskeletal discomforts together in the current FA would be due to the high prevalence of musculoskeletal discomforts. Previous studies also revealed that "musculoskeletal discomforts" are the most prevalent and troublesome discomforts among PMW in the Sri Lankan context (Goonaratna et al., 1999; Waidyasekera et al., 2009; Rathnayake et al., 2019).

The ability of the MENQOL questionnaire to differentiate PMW who were symptomatic and asymptomatic indicates that its discriminant validity 
is consistent with the Chinese validation (Nie et al., 2017) tested against Kuppaman's Index. Therefore, this tool could be used in making therapeutic decisions in symptomatic PMW once a suitable intervention threshold is determined. Furthermore, the tool is adequately sensitive to measure the discomforts, their severity and HRQOL appropriately, as it showed satisfactory concurrent validity measured against MRS. Cited studies, however, have not focused on concurrent validity (Malhan et al., 2008; Van Dole et al., 2012; Ghazanfarpour et al., 2014).

This study has a few strengths. It used a randomly selected sample of women from a semi urban setting for this analysis and although they are not representative of the entire population, they do represent a majority of PMW in the country. Further, a relatively larger sample was used for this study. The authors recommend future studies to perform confirmatory FA to verify the results observed in the current study, as they were unable to perform confirmatory FA due to the scarcity of software. Validation of different languages of MENQOL questionnaire versions is also encouraged, as Sri Lanka is a multi- ethnic country.

\section{CONCLUSIONS}

The Sinhala version of MENQOL questionnaire is a reliable and a valid tool which is informative for determining menopausal discomforts, their severity and HRQOL in PMW conversant in the Sinhala language. Researchers and clinicians can use this tool in both community and clinical setting to plan necessary investigations and treatments and for future research purposes.

\section{CONFLICTS OF INTERESTS}

The authors declare that they have no conflicts of interests.

\section{ACKNOWLEDGMENT}

The authors wish to express sincere gratitude to the Faculty Research Grant (2014-2015), Faculty of Medicine, University of Ruhuna, Sri Lanka and National Research Council (NRC 15-023), Sri Lanka, for funding the study. And further, professionals involved in forward and backward translations; Dr. Thilini Udalwaththa, Ms. Chalanika Vidanapathirana, Ms. Madhushika Ukwaththa, Ms. Thilini Wanniarachchi, Ms. Pramudika Kariyawasam and Ms. Hemamali Madushanthi are acknowledged.

\section{NB}

This manuscript was derived from the corresponding author's PhD study at University of Ruhuna, Sri Lanka.

\section{REFERENCES}

Arafat, S. Y., Chowdhury, H. R., Qusar, M. S. \& Hafez, M. A. (2016) Cross cultural adaptation \& psychometric validation of research instruments: A methodological review, Journal of Behavioral Health, 5(3), pp: 129-136 [Online] Available from: http://www.scopemed.org/?mno $=227223$ [Accessed: $3^{\text {rd }}$ August 2017].

DOI: https://doi.org/10.5455/jbh.20160615121755

Chen, Y., Lin, S. Q., Wei, Y., Gao, H. L., Wang, S. H. \& $\mathrm{Wu}, \mathrm{Z}$. L. (2008) Impact of menopause on quality of life in community-based women in China, Menopause, 15(1), pp: 144-149 [Online] Available from: https://www.ncbi.nlm.nih. gov/pubmed/18030176 [Accessed: $10^{\text {th }}$ November 2016].

DOI: https://doi.org/10.1097/gme.0b013e318115150e

Field, A. (2009) Discovering statistics using SPSS, London: Sage Publications Ltd.

Forouhari, S., Khajehei, M., Moattari, M., Mohit, M., Rad, M. S. \& Ghaem, H. (2010) The effect of education and awareness on the quality-of-life in postmenopausal women, Indian journal of community medicine: official publication of Indian Association of Preventive \& Social Medicine, 35(1), p. 109 [Online] Available from: https://www.ncbi.nlm.nih.gov/pmc/ articles/PMC2888337 [Accessed: $10^{\text {th }}$ November 2016].

DOI: https://doi.org/10.4103/0970-0218.62563

Ghazanfarpour, M., Kaviani, M., Rezaiee, M., Ghaderi, E. \& Zandvakili, F. (2014) Cross cultural adaptation of the menopause specific questionnaire into the Persian language, Annals of Medical and Health Sciences Research, 4(3), pp: 325-329 [Online] Available from: https://www.ajol.info/index. php/amhsr/article/view/112163 [Accessed: 10 ${ }^{\text {th }}$ November 2016].

DOI: https://doi.org/10.4103/2141-9248.133453

Goonaratna, C., Fonseka, P. \& Wijeywardene, K. (1999) Perimenopausal symptoms in Sri Lankan women, The Ceylon Medical Journal, 44(2), pp: 63-69 [Online] Available from: https://europepmc.org/article/med/10565071 [Accessed: $10^{\text {th }}$ November 2016].

Hair, J. F., Anderson, R. E., Tahtam, R. L. \& Balck, V. C. (1995) Multivarite Data Analysis with Reading, New Jersey: Prentice Hall. International Inc, A Viacorn Company.

Harlow, S. D., Gass, M., Hall, J. E., Lobo, R., Maki, P., Rebar, R. W., Sherman, S., Sluss, P. M., De Villiers, T. J. \& STRAW+ 10 Collaborative Group (2012) Executive summary of the Stages of Reproductive Aging Workshop +10 : addressing the unfinished agenda of staging reproductive aging, The Journal of Clinical Endocrinology \& Metabolism, 97(4), pp: 11591168 [Online] Available from: https://pubmed.ncbi.nlm.nih. 
gov/22344196/ [Accessed: $10^{\text {th }}$ November 2016].

DOI: https://doi.org/10.1210/jc.2011-3362

Heinemann, K., Ruebig, A., Potthoff, P., Schneider, H. P., Strelow, F. \& Heinemann, L. A. (2004) The Menopause Rating Scale (MRS) scale: a methodological review, Health and Quality of life Outcomes, 2(1), p. 45 [Online] Available from: https://www.ncbi.nlm.nih.gov/pmc/articles/PMC516787/ [Accessed: $10^{\text {th }}$ November 2016].

DOI: https://doi.org/10.1186/1477-7525-2-45

Hilditch, J. R., Lewis, J., Peter, A., van Maris, B., Ross, A., Franssen, E., Guyatt, G. H., Norton, P. G. \& Dunn, E. (1996) A menopause-specific quality of life questionnaire: development and psychometric properties, Maturitas, 24(6), pp: 161175 [Online] Available from: https://pubmed.ncbi.nlm.nih. gov/8844630/ [Accessed: $10^{\text {th }}$ November 2016].

DOI: https://doi.org/10.1016/0378-5122(96)01038-9

Jenabi, E., Shobeiri, F., Hazavehei, S. M. \& Roshanaei, G. (2015) Assessment of questionnaire measuring quality of life in menopausal women: a systematic review, Oman Medical Journal, 30(3), p. 151 [Online] Available from: https://www. ncbi.nlm.nih.gov/pmc/articles/PMC4459162/ [Accessed: 10 ${ }^{\text {th }}$ November 2016].

DOI: https://doi.org/10.5001/omj.2015.34

Kothiyal, P. \& Sharma, M. (2013) Postmenopausal Quality of Life and associated factors-A, Journal of Scientific and Innovative Research, 2(4), pp: 814-823 [Online] Available from: http://www.jsirjournal.com/Vol2Issue4013.pdf [Accessed: $10^{\text {th }}$ November 2020].

Kupperman, H. S., Blatt, M. H., Wiesbader, H. \& Filler, W. (1953) Comparative clinical evaluation of estrogenic preparations by the menopausal and amenorrheal indices, The Journal of Clinical Endocrinology \& Metabolism, 13(6), pp: 688-703 [Online] Available from: https://pubmed.ncbi.nlm. nih.gov/13061588/ [Accessed: $10^{\text {th }}$ November 2020].

DOI: https://doi.org/10.1210/jcem-13-6-688

Malhan, S., Oksuz, E. \& Tulunay, F. C. (2008) Turkish cultural adaptation and validation of the menopause-specific quality of life questionnaire, Value in Health, 11(6), p. A425 [Online] Available from: https://core.ac.uk/download/pdf/81148123.pdf [Accessed: $10^{\text {th }}$ November 2016].

DOI: https://doi.org/10.1016/S1098-3015(10)66437-6

Nie, G., Yang, H., Liu, J., Zhao, C. \& Wang, X. (2017) Psychometric properties of the Chinese version of the Menopause-Specific Quality-of-Life questionnaire, Menopause (New York, NY), 24(5), p. 546 [Online] Available from: https:// pubmed.ncbi.nlm.nih.gov/27922934/ [Accessed: 3 ${ }^{\text {rd }}$ August 2018].

DOI: https://doi.org/10.1097/GME.0000000000000784

Nisar, N. \& Sohoo, N. A. (2009) Frequency of menopausal symptoms and their impact on the quality of life of women: a hospital based survey, JPMA, 59(11), pp: 752-56 [Online] Available from: https://pubmed.ncbi.nlm.nih.gov/20361673/ [Accessed" 10 ${ }^{\text {th }}$ November 2016].
Rathnayake, N., Lenora, J., Alwis, G. \& Lekamwasam, S. (2018) Cross cultural adaptation and analysis of psychometric properties of Sinhala version of Menopause Rating Scale, Health and Quality of Life Outcomes, 16(1), p. 161 [Online] Available from: https://www.ncbi.nlm.nih.gov/pmc/articles/ PMC6080547/ [Accessed: $3^{\text {rd }}$ October 2018].

DOI: https://doi.org/10.1186/s12955-018-0977-9

Rathnayake, N., Lenora, J., Alwis, G. \& Lekamwasam, S. (2019) Prevalence and severity of menopausal symptoms and the quality of life in middle-aged women: a study from Sri Lanka. Nursing Research and Practice, 2019 [Online] Available from: https://www.hindawi.com/journals/nrp/2019/2081507/ [Accessed: $5^{\text {th }}$ Sepetember 2019].

DOI: https://doi.org/10.1155/2019/2081507

Saxena, S., Orley, J. \& WHOQOL Group (1997) Quality of life assessment: the World Health Organization perspective, European Psychiatry, 12, pp: 263s-266s [Online] Available from: https://pubmed.ncbi.nlm.nih.gov/19698578/ [Accessed: $10^{\text {th }}$ November 2016].

DOI: https://doi.org/10.1016/S0924-9338(97)89095-5

Schneider, H. P. G., Heinemann, L. A. J., Rosemeier, H. P., Potthoff, P. \& Behre, H. M. (2000) The Menopause Rating Scale (MRS): comparison with Kupperman Index and Qualityof-life Scale SF-36, Climacteric, 3(1), pp: 50-58 [Online] Available from: https://pubmed.ncbi.nlm.nih.gov/11910610/ [Accessed: 10 ${ }^{\text {th }}$ November 2020].

DOI: https://doi.org/10.3109/13697130009167599

Shobeiri, F., Jenabi, E., Hazavehei, S. M. M. \& Roshanaei, G. (2016) Quality of life in postmenopausal women in Iran: a population-based study, Journal of Menopausal Medicine, 22(1), pp: 31-38 [Online] Available from: https:// www.ncbi.nlm.nih.gov/pmc/articles/PMC4854657/ [Accessed: $3^{\text {rd }}$ August 2017].

DOI: https://doi.org/10.6118/jmm.2016.22.1.31

Sri Lanka, Department of Census and Statistics (2014) The Sri Lankan Women : Partner in Progress, Colombo: Department of Census and Statistics.

Sydora, B. C., Fast, H., Campbell, S., Yuksel, N., Lewis, J. E. \& Ross, S. (2016) Use of the Menopause-Specific Quality of Life (MENQOL) questionnaire in research and clinical practice: a comprehensive scoping review, Menopause, 23(9), pp: 10381051 [Online] Available from: https://pubmed.ncbi.nlm.nih. gov/27300115/ [Accessed: $3^{\text {rd }}$ August 2017].

DOI: https://doi.org/10.1097/GME.0000000000000636

Van Dole, K. B., DeVellis, R. F., Brown, R. D., Funk, M. L. J., Gaynes, B. N. \& Williams, R. E. (2012) Evaluation of the Menopause-Specific Quality of Life Questionnaire: a factoranalytic approach, Menopause, 19(2), pp: 211-215 [Online] Available from: https://pubmed.ncbi.nlm.nih.gov/22282042/ [Accessed: 10 ${ }^{\text {th }}$ November 2016].

DOI: https://doi.org/10.1097/gme.0b013e31822817f9 
von Mühlen, D. G., Kritz-Silverstein, D. \& Barrett-Connor, E. (1995) A community-based study of menopause symptoms and estrogen replacement in older women, Maturitas, 22(2), pp: 71-78 [Online] Available from: https://psycnet.apa.org/ record/1996-28107-001 [Accessed: $10^{\text {th }}$ November 2020].

DOI: https://doi.org/10.1016/0378-5122(95)00917-A

Waidyasekera, H., Wijewardena, K., Lindmark, G. \& Naessen, T. (2009) Menopausal symptoms and quality of life during the menopausal transition in Sri Lankan women, Menopause, 16(1), pp: 164-170 Available from: https://pubmed.ncbi.nlm.nih. gov/18703984/ [Accessed: $10^{\text {th }}$ November 2016].

DOI: https://doi.org/10.1097/gme.0b013e31817a8abd

Williams, R. E., Kalilani, L., DiBenedetti, D. B., Zhou, X., Granger, A. L., Fehnel, S. E., Levine, K. B., Jordan, J. \& Clark, R. V. (2008) Frequency and severity of vasomotor symptoms among peri-and postmenopausal women in the United States,
Climacteric, 11(1), pp: 32-43 [Online] Available from:

https://pubmed.ncbi.nlm.nih.gov/18202963/ [Accessed: 10 ${ }^{\text {th }}$ November 2016].

DOI: https://doi.org/10.1080/13697130701744696

Williams, R. E., Levine, K. B., Kalilani, L., Lewis, J. \& Clark, R. V. (2009) Menopause-specific questionnaire assessment in US population-based study shows negative impact on healthrelated quality of life, Maturitas, 62(2), pp: 153-159 [Online] Available from: https://pubmed.ncbi.nlm.nih.gov/19157732/ [Accessed: $10^{\text {th }}$ November 2016].

DOI: https://doi.org/10.1016/j.maturitas.2008.12.006

Zöllner, Y. F., Acquadro, C. \& Schaefer, M. (2005) Literature review of instruments to assess health-related quality of life during and after menopause, Quality of Life Research, 14(2), pp: 309-327 [Online] Available from: https://pubmed.ncbi. nlm.nih.gov/15892422/ [Accessed: $10^{\text {th }}$ November 2016]. DOI: https://doi.org/10.1007/s11136-004-0688-z 